\title{
Genotoxicity and carcinogenicity of cobalt-, nickel- and copper-based nanoparticles (Review)
}

\author{
RUTH MAGAYE $^{1}$, JINSHUN ZHAO $^{1}$, LINDA BOWMAN ${ }^{2}$ and MIN DING $^{2}$ \\ ${ }^{1}$ Department of Preventive Medicine of the Medical School, Zhejiang Provincial Key Laboratory of Pathological and \\ Physiological Technology, Ningbo University, Ningbo, Zhejiang 315211, P.R. China; \\ ${ }^{2}$ Pathology and Physiology Research Branch, Health Effects Laboratory Division, \\ National Institute for Occupational Safety and Health, Morgantown, WV 26505, USA
}

Received April 28, 2012; Accepted July 31, 2012

DOI: $10.3892 / \mathrm{etm} .2012 .656$

\begin{abstract}
The nanotechnology industry has matured and expanded at a rapid pace in the last decade, leading to the research and development of nanomaterials with enormous potential. The largest source of these nanomaterials is the transitional metals. It has been revealed that numerous properties of these nano-sized elements are not present in their bulk states. The nano size of these particles means they are easily transported into biological systems, thus, raising the question of their effects on the susceptible systems. Although advances have been made and insights have been gained on the effect of transitional metals on susceptible biological systems, there still is much ground to be covered, particularly with respect to our knowledge on the genotoxic and carcinogenic effects. Therefore, this review intends to summarize the current knowledge on the genotoxic and carcinogenic potential of cobalt-, nickel- and copper-based nanoparticles indicated in in vitro and in vivo mammalian studies. In the present review, we briefly state the sources, use and exposure routes of these nanoparticles and summarize the current literature findings on their in vivo and in vitro genotoxic and carcinogenic effects. Due to the increasing evidence of their role in carcinogenicity, we have also included studies that have reported epigenetic factors, such as abnormal apoptosis, enhanced oxidative stress and pro-inflammatory effects involving these nanoparticles.
\end{abstract}

\section{Contents}

1. Introduction

2. Genotoxicity and carcinogenicity of cobalt-based nanoparticles

Correspondence to: Professor Jinshun Zhao, Department of Preventive Medicine of the Medical School, Zhejiang Provincial Key Laboratory of Pathological and Physiological Technology Ningbo University, 818 Fenghua Road, Ningbo, Zhejiang 315211, P.R. China E-mail: zhaojinshun@nbu.edu.cn

Key words: genotoxicity, carcinogenicity, nanoparticles, cobalt, nickel, copper
3. Genotoxicity and carcinogenicity of nickel-based nanoparticles

4. Genotoxicity and carcinogenicity of copper-based nanoparticles

5. Conclusion

\section{Introduction}

In the new millennium, nanotechnology has broadened the horizon for innovators, producers and consumers in almost all sectors, by enabling the engineering of functional systems at the molecular level. Currently, materials derived from this technology are used in catalysis and electronics, two-dimensional nanotubes and nanowires for optical and magnetic systems, and as nanoparticles used in cosmetics, pharmaceuticals and coatings (1). Nanoparticles are particles or objects with at least one of their three dimensions in the range of 1-100 $\mathrm{nm}(2,3)$. Nanoparticles have existed in our natural environments (volcanic ash, ocean spray, magnetotactic bacteria and mineral composites) before engineered nanoparticles were produced or were unintentionally produced (by-products of industrial processes) (4). Engineered nanomaterials, including nanoparticles and nanofibers, are generally classified into carbon-based materials, metal-based materials, dendrimers and composites (5,6). Although humans and the environment have been able to tolerate, avoid or adapt to naturally occurring nanoparticles, what is of relevance now is the intentional and unintentional production of nanoparticles and their accumulation that pose a potential environmental and health risk.

The quantum properties these nanoscale particles possess make them unpredictable and, thus, may cause toxicity, which may lead to genotoxicity and carcinogenicity. The key factor in nanoparticle toxicity is their minute size, apart from the chemical composition, shape and particle aging. Often smaller than cellular organelles and cells, this allows the penetration of basic biological structures, which may in turn disrupt their normal function $(7,8)$. In addition, the physical and chemical properties of a nanoparticle cannot be simply predicted from the properties of a fine particle with the same chemical composition. This is supported by studies which have shown 
that nanoparticles are more toxic than the corresponding fine particles (9-14).

The possible toxic effects that are caused by nanoparticles include tissue inflammation and altered cellular redox balance toward oxidation, which causes abnormal cell function or cell death. Oxidative stress is a normal cellular process involved in numerous aspects of cellular signaling (15-17). Oxidative stress results as a consequence of an imbalance between the production and manifestation of reactive oxygen species (ROS), and the ability of biological systems to readily detoxify the reactive intermediates or to repair the resulting damage. Elevated cellular oxidative stress has been noted by numerous studies following exposure to nanoparticles of different metals $(11,18-24)$. In addition, the intracellular response to nanoparticles, degree of cytotoxicity and potential mechanism of toxicity of cells to nanoparticles is also dependent on the target cell type (25). These cells include those that are located at the most likely points of entry for nanoparticles, such as the lungs, skin and gastrointestinal tract (GIT). Other possible routes of exposure, as in the field of medicine, are through injection and implantation $(26,27)$.

Recently, numerous studies have evaluated the potential for genotoxicity and carcinogenicity of metal-based nanoparticles, particularly cobalt-, nickel- and copper-based nanoparticles. This review focuses on current knowledge on the potential for genotoxicity and carcinogenicity of cobalt-, nickel- and copper-based nanoparticles used in in vitro and in vivo mammalian studies. In addition, studies that have indicated epigenetic factors, such as enhanced oxidative stress, pro-inflammatory effects and abnormal apoptosis in their results are also considered.

\section{Genotoxicity and carcinogenicity of cobalt-based nano- particles}

Sources of cobalt. Naturally, cobalt occurs as only one stable isotope, cobalt 59. However, through neutron activation of cobalt 59, another isotope named cobalt 60 is produced. Cobalt 60 is a commercially important radioisotope used as a radioactive tracer, in the production of $\gamma$-rays and as cold sterilization for food in certain countries. In animals, cobalt forms the center of the coenzyme cobalamin or vitamin B12, which is an essential trace element.

Uses of cobalt nanoparticles. As a nanoparticle, cobalt's metallic form appears black. Cobalt-based nanoparticles may be produced as cobalt oxide, organic metal compounds or biopolymers (28). In biomedical applications, cobalt-based nanoparticles are used as starting materials for the formation of magnetic polymer microspheres and dextran coating. Colloidal cobalt nanoparticles, such as cobalt ferrite $\left(\mathrm{CoFe}_{2} \mathrm{O}_{4}\right)$, have applications in information storage and energy (29). In medicine, cobalt has been known as a highly effective magnetic resonance imaging (MRI) contrast agent, in combination with gold (30), iron and graphite (31), and platinum (32). It has also been investigated for use in cancer therapy (32) and anaerobic waste water treatment (32-34).

Cobalt nanoparticle exposure. Human exposure to cobalt occurs from industry, the environment or after joint replace- ment from the cobalt-chrome alloy in implants. In occupational settings, exposure to cobalt and its compounds may lead to various lung diseases, including interstitial pneumonitis, fibrosis and asthma (27,35-37). The carcinogenic potential of cobalt and its compounds were evaluated by IARC in 1991, which concluded that there was inadequate evidence for carcinogenicity in humans (lung cancer) but sufficient evidence in experimental animals $(36,38)$. In recent years, the application of cobalt nanoparticles ranges from industry to medicine, but research data on the bio-effects, particularly in comparison with their fine size particles, are limited. This is likely due to their relatively short history of production and application. In addition, it should be mentioned that little is specifically known about the toxicology of cobalt metal particles including both fine and nanoparticles, likely since it was assumed, as for other metals, that the biological activity of a metal particle, including genotoxicity and carcinogenicity, was mediated by the ionic form and could be determined by evaluating its soluble compound (36). However, evidence shows that, in contrast to what is generally hypothesized for the majority of metals, the biological activity of cobalt metal particles is not exclusively mediated by the ionic form dissolved in biological media (36).

\section{In vitro studies}

Cobalt nanoparticles. Cobalt metals are known to be genotoxic in vitro, whereas cobalt ions are known to be carcinogenic to rodents (39). Reviews on cobalt compounds (40) and metal particles (36) have surmised that cobalt (compound or metal) particles are genotoxic. These conclusions were reached based on the effects of cobalt metals and compounds on mammalian cells in vitro. The genotoxic effects noted included DNA strand breaks, sister chromatid exchanges and aneuploidy, morphological transformation (40) and interference with repair processes of damaged DNA (36). These results were in part, similar to those induced by cobalt nanoparticles. According to a study on BALB/3T3 mouse fibroblast cells, it was observed that cobalt nanoparticles $(>1 \mu \mathrm{M})$ induced an increased production of single- and double-strand DNA breaks as well as chromosomal aberrations in the form of micro-nucleate binucleate cells (41). However, this was shown to be reduced at higher concentrations $(100 \mu \mathrm{M})$. In addition, cobalt nanoparticles induced a significant increase in the formation of type III foci (morphologically transformed colonies). Studies that used peripheral leukocytes have also shown cobalt nanoparticles to be genotoxic, when compared with cobalt ions $\left(\mathrm{Co}^{2+}\right)$ in a dose-dependent manner. Genotoxicity was shown as increases in the \% tail DNA shown by the comet assay (42) and positive results of micro-nulceate binucleate cells provided by the micronucleus test (42). In these studies, the particle size ranged from 100 to $500 \mathrm{~nm}$. The increase in pseudotumors due to prosthetic implants led Kwon et al (43) to investigate the cause. They demonstrated that at a particle size of 30-35 nm, cobalt nanoparticles showed cytotoxicity in macrophages in vitro at a concentration of $1 \times 10^{12}$ particles $/ \mathrm{ml}$. They postulated that the high concentration of cobalt required for toxicity of macrophages in vitro meant that there was an increased production of cobalt nanoparticles in vivo. Thus, ingestion of the nanoparticles by macrophages produces pseudo-tumors at implant sites. Marked differences on pro-inflammatory response and oxidative stress by cobalt 
nanoparticles in human endothelial cells in vitro were observed in another study (44).

These findings suggest that nano-sized cobalt particles are internalized by human leukocytes and interact with DNA, leading to the observed genotoxic effects. Therefore, including fibroblast cells, it can be postulated that cobalt nanoparticles have a genotoxic effect on the reticuloendothelial system.

Cobalt-chrome nanoparticles. Numerous other studies used the cobalt-chrome alloy nanoparticle to conduct their research, in the majority of these studies the fibroblast cell was predominantly used (45-48), and almost all observed cobalt-chrome nanoparticles to be cytotoxic and genotoxic to this cell line. For example, a study comparing fine and nanoparticle alloys of cobalt-chrome on human fibroblast cells at equivalent volumetric doses noted that the nanoparticles generated free radicals, cell DNA damage, cytotoxicity and aneuploidy (45). A complex form of aneuploidy was also reported by Figgitt et al (46) who conducted similar studies on human fibroblast cells that were derived from the peripheral blood of individuals exposed to cobalt-chrome and cobalt (II). Other studies have reported that cobalt-chrome increased the production of micro-nucleate binucleate cells (47), caused chromosomal losses, gains and deletions (47), tetraploidy (49) and DNA double-strand breaks (49). In a study conducted by Bhabra et al (48), it was reported that cobalt-chrome nanoparticles $(29.5 \mathrm{~nm})$ damage human fibroblast cellular DNA across an intact cellular barrier without crossing the barrier. They suggested that the damage is mediated by a novel mechanism involving transmission of purine nucleotides (such as ATP) and intercellular signaling within the barrier through connexin gap junctions or hemi-channels and pannexin channels.

An elevated cellular inflammatory response has been noted in numerous studies following exposure to nanoparticles (50-54), including cobalt nanoparticles. Guildford et al (55) investigated the effect of various types of nanoparticles on key components of the host response, such as clot formation and inflammatory cells. The results showed that cobalt nanoparticles $(28 \mathrm{~nm})$ stimulated cells to acquire a macrophage phenotype able to secrete higher levels of the pro-inflammatory cytokine, tumor necrosis factor $\alpha$ (TNF $\alpha)$. A large variety of soluble factors, including cytokines [e.g. interleukins (IL)] and tumor necrosis factor (TNF) protein families, migration inhibition factors, ROS and reactive nitrogen species, are inflammatory response factors which mediate inflammation. Under normal physiological conditions, these factors are important protective defenses against tissue injury or infection. However, they are also capable of promoting DNA damage, such as chromosomal fragmentation, DNA point mutations, inhibition of DNA repair and formation of methylation patterns that may lead to altered gene expression profile and the formation of DNA adducts (56). In addition, recent research evidence revealed that the inflammatory microenvironment in and around tumors is an indispensable participant in the neoplastic process (57).

The majority of studies conducted on cobalt-chrome alloys mentioned presently indicate nanoparticles of cobalt-chrome alloys to be genotoxic. The genotoxicity was either via genetic factors, such as chromosomal aberrations and DNA damage in the form of single- and double-strand breaks, or via transmis- sion of nucleotides through gap junctions. They may even cause genotoxicity through epigenetic factors, such as inflammation.

Cobalt-oxide nanoparticles. Engineered cobalt oxide $\left(\mathrm{Co}_{3} \mathrm{O}_{4}\right)$ nanoparticles were shown to enter cells rapidly and remain confined to vesicles, thus causing a rapid induction of ROS in human cell lines (58).

Tungsten carbide-cobalt (WC-Co) nanoparticles. In an in vitro study (59), when tested over a range of cobalt equivalent concentrations $(1.5-15 \mu \mathrm{g} / \mathrm{ml})$, WC-Co particles were shown to cause significantly more DNA breaks than cobalt metal particles alone, both on isolated human DNA and in cultured human lymphocytes (alkaline elution and comet assays). In addition, this DNA damage could be inhibited by scavenging activated oxygen species. In another study, WC-Co nanoparticles were demonstrated to induce a higher level of oxidative stress and activated the activator protein-1 (AP-1) and nuclear factor- $\kappa \mathrm{B}$ $(\mathrm{NF}-\kappa \mathrm{B})$ more efficiently in $\mathrm{JB}^{+/+}$cells than WC-Co fine particles (60). It also had a high potency to stimulate mitogenactivated protein kinases (MAPKs), including extracellular signal regulated kinases (ERKs), P38 and c-Jun N-terminal kinases (JNKs). In human keratinocyte cells (HaCaT) at concentrations of $3 \mu \mathrm{g} / \mathrm{ml}$ for an exposure of $3 \mathrm{~h}$ and 3 days, WC-Co nanoparticles were able to exert responses similar to those of free cobalt ions $\left(\mathrm{CoCl}_{2}\right)$, particularly the induction of hypoxia-like effects via interactions with HIF-1 $\alpha$ in human keratinocytes (61). In a study performed on WC-Co nanoparticles, it was concluded that ROS may act as a major contributor in nano WC-Co particle-induced adverse health effects (62).

WC-Co nanoparticles cause genotoxicity via DNA damage, oxidative stress, activation of activator proteins and proteins in the mitogenic pathways. These were confirmed by studies which compared fine and nanoparticles of WC-Co.

Cobalt-ferrite nanoparticles. Cobalt-ferrite nanoparticles $\left(\mathrm{CoFe}_{2} \mathrm{O}_{4} ; 6-12 \mathrm{~nm}\right)$ were used to investigate the interaction with nucleic acid (63). The investigators in this study observed that the research data collectively revealed that there was an interaction between $\mathrm{CoFe}_{2} \mathrm{O}_{4}$ nanoparticles and nucleic acid. The investigators presumed that the linkage was based on a coordination interaction of the phosphate groups and the oxygen atoms on the heterocyclic bases of DNA with metal ions on the particle surface.

The in vitro studies demonstrated that cobalt nanoparticles induced DNA strand breaks, micronuclei formation, chromosomal aberrations (aneuploidy, polyploidy and tetraploidy) and morphological transformation of mammalian cell lines. Cobalt nanoparticles exhibited higher genotoxicity than cobalt fine particles and ions. Cobalt nanoparticles were also shown to cause inflammation and oxidative stress. They are also proven to have toxic effects towards both anchorage and non-anchorage cells in vitro, and the majority of these findings were derived from studies performed on fibroblast cells. This may be due to the increased use of a cobalt-chrome alloy in replacement surgeries.

\section{In vivo studies}

Only one in vivo study was retrieved for the evaluation of the carcinogenesis of cobalt nanoparticles. Hansen et al (64) 
implanted cobalt fine particles and nanoparticles (50 and $200 \mathrm{~nm}$ ) bilaterally (i.e. subcutaneously with fine particles, and intramuscularly with nanoparticles for each animal) at the vertebral column of rats to investigate the carcinogenesis of cobalt particles. In five out of six implanted rats, the sites of nanoparticle implantation developed nodules. Morphological and histochemical biomarker investigations revealed that these nodules were malignant mesenchymal tumors. On the contrary, malignant mesenchymal tumors were not observed around the fine particles. In the subcutaneous area of fine particle implantation, discrete fibrosis and discrete inflammatory infiltrate were observed, but not granulomas. A model of the neoplasia sequence for the carcinogenesis of cobalt nanoparticles was summarized as follows: inflammation $\rightarrow$ preneoplasia $\rightarrow$ neoplasia. This difference in carcinogenic potency suggests the need to develop a separate risk estimate for cobalt fine and nanoparticles, and to develop separate recommendations for occupational and environmental exposures to each size range. However, there is also a need for further in vivo animal studies and epidemiological investigations.

The experimental evidence indicates that both cobalt fine and nanoparticles exert certain genotoxic and carcinogenic activity in in vitro and in vivo experimental systems. In addition, one in vivo study in rats demonstrated that cobalt nanoparticles induced malignant mesenchymal tumors, whereas cobalt fine particles did not at the equivalent treatment dose. Since there is evidence of genotoxicity in the studies that have utilized fibroblast cells, in vivo animal studies and epidemiological investigations that focus on replacements or implants that are cobalt-based are recommended.

\section{Genotoxicity and carcinogenicity of nickel-based nano- particles}

Sources of nickel. Nickel is the fifth most abundant element in the world. Approximately $85 \%$ of nickel is used in combination with other metals to make alloys, the best known of which is stainless steel.

Uses of nickel nanoparticles. Alloys of nickel are used in the home, architecture, health care, food processing and throughout industry. Non-alloys of nickel are used in nickel plating and chemical applications, including in rechargeable batteries, electronics, power tools, transport and emergency power supplies. Nickel-based nanoparticles have a wide variety of applications in industry. For example Ban et al (65) investigated alloys of copper and nickel at the nanometer scale for use in controlled magnetic hyperthermia applications. Metallic nickel nanoparticles have also shown potential for use as electrode materials in multilayer ceramic capacitors (MLCC) (66). Researchers have also explored the potential for nickel nanoparticles in the form of nanorings as memory cells (67). Zhao et al (68) conducted a comprehensive general review of nickel and nickel compounds.

Nickel nanoparticle exposure. Lung inhalation is the major route of nickel exposure. However, it may also be ingested or absorbed through the skin. The primary target organs are the lungs and kidneys (69). According to Kasprzak et al (70) 'the most adverse effects of exposure to nickel are skin allergies, lung fibrosis, and lung cancer'. Some of the common nickel compounds are nickel oxide $(\mathrm{NiO})$, nickel chloride $\left(\mathrm{NiCl}_{2}\right)$ and nickel sulphide $\left(\mathrm{Ni}_{2} \mathrm{SO}_{4}\right)$. Nickel compounds are classified by IARC as group 1, carcinogenic to humans. Whereas, metallic nickel is classed as group $2 \mathrm{~B}$, possibly carcinogenic to humans. In 2008, nickel was voted as the allergen of the year by the American Contact Dermatitis Society following an article by Kornick and Zug (71) on nickel. Numerous experimental and epidemiological studies, as well as reviews, have shown metallic nickel and nickel compounds to be carcinogenic (72-77).

Nickel-based nanoparticles are new products and have been widely used in industry in recent years $(78,79)$. Their characteristics include a high level of surface energy, high magnetism, low melting point, high surface area and low burning point. However, concerns have been expressed that these same properties of nickel-based nanoparticles may present unique bioactivity and challenges to human health (80). Although little is known about the effects of particle size relative to speciation, it is worth mentioning that the size of the nickel-based nanoparticles may play an important role in the biological effects (81).

\section{In vitro studies}

Nickel nanoparticles. Numerous studies have examined the genotoxicity of nickel compounds by using various toxicological test systems in the past 30 years (68). The genotoxicity of metallic nickel fine and nanoparticles has not been demonstrated yet, except for the indications of a few studies. When compared to the known genotoxic compound titanium oxide, alveolar epithelial (A549) cells exposed to nickel nanoparticles $(100 \mathrm{~nm})$ caused greater apoptotic damage in both flow cytometry and DNA fragmentation studies (82). The extent of DNA fragmentation was increased by $20-24 \%$. The investigators in this study suggested that these effects were attributable to ROS generation. Apoptotic DNA fragmentation is a key feature of apoptosis, where DNA is cleaved into internucleosomal fragments of $180 \mathrm{bp}$ (83), in response to a variety of apoptotic stimuli in a diverse range of cells. Studies performed on other nanoparticles have summarized that oxidative stress may be a key route in inducing the cytotoxicity of nanoparticles according to their findings $(18,84,85)$. Apoptosis was also observed in the mouse epithelial (JB6) cell line by Zhao et al (86). It was observed that metallic nickel nanoparticles $(92.32 \mathrm{~nm})$ caused higher cytotoxicity and apoptotic induction than fine particles $(3.34 \mu \mathrm{m})$ after a 24-h exposure of JB6 cells to $0.1-20 \mu \mathrm{g} / \mathrm{cm}^{2}$ of nickel nano or fine particles. They concluded that the $\mathrm{Bcl}-2$ and $\mathrm{Akt}$ (used as endpoints) may play a role in preventing the release of cytochrome $c$ from the mitochondria into the cytoplasm. ROS cause cell death via necrotic or apoptotic pathways. The mechanisms of cell death via ROS generation include receptor activation, caspase activation, Bcl-2 family proteins and mitochondrial dysfunction $(17,87)$. These findings were similar to studies conducted on leukemia cells (K562 cells) where it was revealed that the nickel nanoparticles capped with positively charged tetraheptylammonium were cytotoxic to these cells at high concentrations, and subsequently induced both apoptosis and necrosis of target cancer cells (88). This demonstrated that functionalized nickel nanoparticles with positively 
charged groups could enhance the permeability of the cell membrane and facilitate the cellular uptake of external target molecules into leukemia K562 cells. In another study nickel nanoparticles caused a rapid and prolonged activation of the hypoxia inducible factor-1 $\alpha$ (HIF-1 $\alpha$ ) pathway, which was stronger than that induced by soluble nickel (II) (89). They concluded that moderate cytotoxicity and sustained activation of the HIF-1 $\alpha$ pathway by metallic nickel nanoparticles could promote cell transformation and tumor progression. The characteristics of this toxicity pathway are similar to those activated by carcinogenic nickel compounds.

Ahamed (90) showed that nickel nanoparticles induced ROS production in a dose- and time-dependent manner in A549 cells treated with $0,1,2,5,10$ and $25 \mu \mathrm{g} / \mathrm{ml}$ nanoparticles for 24-48 h. This was indicated by a depletion of GSH and induction of ROS and lipid peroxidation (LPO). They also showed that nickel nanoparticles reduced mitochondrial function and induced the leakage of lactate dehydrogenase (LDH) in a dose- and time-dependent manner. Nickel nanoparticles $(62 \mathrm{~nm})$ were capable of promoting the polymerization of fibrin and the aggregation and fragmentation of platelets, leading to a moderately activated monocyte phenotype (55). Marked differences in oxidative stress and pro-inflammatory responses by nickel nanoparticles in human endothelial cells in vitro were also observed in another study (44).

Nickel nanoparticle genotoxicity was shown by increased DNA fragmentation that led to apoptosis. Nickel nanoparticles also caused cell death by generating ROS either by caspase activation, activation of the Bcl-2 family, activation of HIF-1 $\alpha$ or mitochondrial dysfunction. Oxidative stress and proinflammatory response were also noted.

Nickel-oxide ( $\mathrm{NiO})$ nanoparticles. $\mathrm{NiO}(20 \mathrm{~nm})$ was observed to increase the gene expression of heme oxygenase-1 (HO-1) and surfactant protein-D (SP-D) in A549 cells (91). The researchers of this study highlighted that an increase in gene expression of stress responsive enzymes, such as HO-1 and SP-D, and translocations of the transcription factor HIF-1 $\alpha$ were caused by $\mathrm{NiO}$ nanoparticles. Pietruska et al (89) provided further evidence on this point. They performed physicochemical characterization of $\mathrm{NiO}$ and metallic nickel particles and ion bioavailability and toxicological properties in human lung epithelial cells (H460). Their results showed that $\mathrm{NiO}$ nanoparticles induced stabilization and nuclear translocation of the HIF-1 $\alpha$ transcription factor followed by upregulation of its target gene, $\mathrm{N}$-myc downstream regulated gene 1/Cap 43 [NDRG1(cap43)]. In this study, cytotoxicity to H460 cells was observed to occur concomitantly with activation of an apoptotic response as determined by dose- and time-dependent cleavage of caspases and PARP.

The level of intracellular ROS was also observed to increase with increasing exposure to nickel oxide nanoparticles $(20 \mathrm{~nm})$ on A549 cells (91). In a study investigating the inflammation potency of nickel oxide (92), well-characterized nanoparticles of nickel oxide were instilled into the lung of rats using two time points ( $24 \mathrm{~h}$ and 4 weeks) to evaluate the acute and chronic effects. The results showed that along with cesium oxide and zinc oxide, nickel and copper oxides at $10-20 \mathrm{~nm}$ and $<50 \mathrm{~nm}$ respectively, had acute and chronic inflammogenic effects on the lung. Acutely, patterns of the lung showed that neutrophil and eosinophil infiltrates differed following instillation. Chronically, the nanoparticles caused neutrophilic, neutrophilic/lymphocytic, eosinophilic/fibrotic/ granulomatous and fibrotic granulomatous inflammation.

The aforementioned studies have shown that both $\mathrm{Ni}$ and $\mathrm{NiO}$ appear to activate the HIF-1 $\alpha$ pathway, which may promote cell transformation and tumor progression. Apoptosis is also a key finding in the Ni nanoparticle studies.

\section{In vivo studies}

In a case study reported by Iannitti et al (93), nickel nanoparticles, including nanoparticles of other heavy metals, were indicated as the causative agents in Hodgkin's lymphoma. Nickel nanoparticles were identified in the bone marrow biopsy and the right inguinal lymph node specimens using field emission gun-environmental scanning electron microscopy (FEG-ESEM) coupled with energy dispersive spectroscopy (EDS). This indicated the presence of heavy metal nanoparticles in cells and their involvement in the onset of Hodgkin's disease. Evidence exists of systemic and pulmonary pathology in a human following exposure to nickel nanoparticles (94), but whether it causes carcinogenicity in animal models is a question that is still being widely investigated. The majority of in vivo studies on nickel nanoparticles have been focused on pulmonary pathology. Gillespie et al (95) used occupationally relevant dose ranges of nickel hydroxide and C57BL/6 mice as their animal models. These forms of nickel-based nanoparticles were used since they are highly favorable for use as a chemical energy source in power or energy markets. Their studies showed that nickel hydroxide nanoparticles are capable of inducing inflammatory effects in the lungs after both short- and longterm exposure periods. Although short-term exposure may cause reversible genetic damage, long-term persistent exposure is to be carefully considered. Long-term exposure renders the cell vulnerable to DNA aberrations that consequently lead to mutagenesis. Rats that were intramuscularly implanted with metallic nickel nanoparticles developed rhabdomyosarcoma in a study (64). However, this study showed that both nickel fine and nanoparticles caused the development of rhabdomyosarcomas. Another study that intratracheally instilled rats with $0.2 \mu \mathrm{g}$ of nickel oxide dispersed in distilled water which had a mass median diameter in water of $26 \mathrm{~nm}$ showed that the expression of macrophage inflammatory protein-1 $\alpha$ (MIP-1 $\alpha$ ) was continually increased in lung tissue and broncho-alveolar lavage fluid (BALF), whereas interleukin-1 $\alpha$ (IL-1 $\alpha$ ) and IL-1 $\beta$ were increased in lung tissue and monocyte chemotactic protein-1 (MCP-1) showed a transient increase in BALF (96). This study examined the induction of 21 cytokines, including inflammation-, fibrosis- and allergy-related, by well-dispersed nickel oxide nanoparticles in lung disorders. It was concluded that overall agglomerates of nickel oxide nanoparticles have a persistent inflammatory effect and that the increase in cytokine expression and persistent increase in CC chemokine ( $\beta$-chemokine) were involved in the persistent pulmonary inflammation. Two different studies by Morimoto et al (97) and Nishi et al (98) obtained similar results in studies conducted on the toxicity of nickel oxide nanoparticle and agglomerates following intratracheal instillation in male Wistar rats. Both Morimoto et al (97) and Nishi et al (98) exposed rats to nickel oxide nanoparticles $(3.3 \mathrm{mg} / \mathrm{kg}$ and $26 \mathrm{~nm}$ mass median 
diameter), and were dissected at 3 days, 1 week, and 1, 3 and 6 months. In both studies, through quantitative measurement of protein by ELISA, the level of cytokine-induced neutrophil chemoattractant (CINC)-2 $\alpha \beta$ was elevated ( 3 days to 6 months and 3 days to 3 months). However, in the study by Nishi et al (98), it was observed that the level of CINC-1 was increased from 3 days to 3 months, and CINC-3 was increased at 3 days, but subsequently decreased. They also observed the infiltration of neutrophils and alveolar macrophages in lung tissue. BALF cell count was also increased consistently, with a significant increase in neutrophil and alveolar macrophage count in both studies. In the study by Morimoto et al (97), it was concluded that nanoparticle agglomerates of nickel oxide induced a persistent inflammatory response, while Nishi et al (98) suggested that CINC was involved in lung injury from nickel oxide nanoparticles. Nickel hydroxide nanoparticles demonstrated stronger inflammogenic potential then the other nanoparticles (99). This study was performed to examine ROS and inflammatory responses in mice exposed to each type of nanoparticle for $4 \mathrm{~h}$ in a whole-body inhalation system. Lipid peroxide levels were increased $24 \mathrm{~h}$ after instillation, but decreased 3 days later in another study where nickel oxide nanoparticles were intratracheally instilled in rats (91).

The in vivo investigations performed with nickel nanoparticles show that nickel nanoparticles cause cancers. They also induce other cellular and molecular effects that have the potential to be carcinogenic, such as inflammation and induction of oxygen radicals. The case studies also show that nickel nanoparticles caused pulmonary pathology similar to those in rats and together with other heavy metal nanoparticles, may cause Hodgkin's lymphoma.

The limited in vitro experimental results show that the nickel nanoparticles induced DNA fragmentation and activation of the HIF-1 $\alpha$ pathway in cultured cells. The nanoparticles also induce persistent inflammation in in vivo rat models explained by increases in inflammatory markers. One in vivo experimental study in rats demonstrated that both nickel nano and fine particles caused the formation of rhabdomyosarcomas and one retrospective case study showed involvement of nickel nanoparticles in Hodgkin's lymphoma.

\section{Genotoxicity and carcinogenicity of copper-based nano- particles}

Sources of copper. Copper in its pure state is rarely found in nature, but it is found combined with other chemicals in an ore. Worldwide, there are approximately 15 copper ore mines in 40 countries. According to a British Geological Survey by Brown et al (100), 15,800,000 tons of copper were produced in the world between 2005 and 2009. Copper is also an essential micronutrient which is necessary for the proper growth, development and maintenance of bone, connective tissue, brain, heart and numerous other organs (101-103). Copper is also involved in the stimulation of the immune system to fight infections, repair injured tissues and promote healing (104), and it also aids neutralization of 'free-radicals', which cause severe cell injury (105). The average level of stored copper in the body (mostly in the liver) is approximately $120-150 \mathrm{mg}$. Copper may be absorbed by the stomach, but the majority is absorbed by the small intestine. In the blood, it is observed bound to proteins. Under normal physiological conditions, copper is mostly excreted via bile that is released into the GIT with minimal copper reabsorbed by intestinal cells. This allows copper to be conserved and tightly regulated. Copper, therefore, is useful in both the physical and the biological aspects of humans.

Uses of copper. Copper is commonly used in the production of electrical wire, household kitchen appliances, pipes and tubes, automobile radiators and as a pigment and preservative for paper, paint, textiles and wood. Copper nanoparticles are used as additives in lubricants, polymers or plastics, metallic coatings and ink $(106,107)$, they are also used as bioactive coatings that are capable of inhibiting target microorganisms such as Escherichia coli and Staphylococcus aureus (108). Copper nanoparticles are also developed for temperature and pressure sensing (109), and as hydrogen catalysts in fuel cells. They are also investigated for use in the design of bioactive nanocomposites, such as biomedical silicones, to give it strong nanoparticle properties (110). Both copper fine and nanoparticles have a wide variety of industrial and commercial uses and are still being explored. This is particularly true for copper nanoparticles.

Copper nanoparticle exposure. Occupational exposure of copper dusts or fumes is harmful to human health, including an increased risk of cancer among copper smelter workers (111). In the early studies on the genotoxicity and carcinogenicity of water soluble copper compounds, such as copper sulfate, they were observed to be genotoxic, with characteristics including the induction of chromosomal aberrations and micronuclei in White Leghorn chick bone marrow cells (112) and chromosomal aberrations in Swiss mice (113). However, the data on the genotoxicity and carcinogenicity of water insoluble copper particles are scarce.

\section{In vitro studies}

Copper nanoparticles. Copper nanoparticles have been demonstrated to be extremely reactive in a simulative intracorporeal environment (114). The reason for this high reactivity was due to copper nanoparticles $(23.5 \mathrm{~nm})$ consuming hydrogen ions in the stomach at a faster rate, which then are converted further into cupric ions whose toxicity is known to be high in vivo. Metal ions are known to have a high affinity for electron-rich molecules such as DNA, but studies have shown that copper nanoparticles are able to interact with DNA. This was demonstrated by a study in which copper nanoparticles (4-5 $\mathrm{nm}$ ) caused a dose-dependent degradation of isolated DNA molecules via the generation of singlet oxygen $\left({ }^{1} \mathrm{O}_{2}\right)$ in 937 and HeLa cells (115). Singlet oxygen is the active species in photodynamic therapy for cancer (116).

Copper-oxide nanoparticles. Since there is a published review paper available with regard to the effects of DNA damage induced by copper oxide nanoparticles in in vitro studies (117), only a few are mentioned here. DNA damage as a result of oxidative stress, identified by increased levels of 8 -isoprostane and the ratio of glutathione disulfide (GSSG) to total glutathione in human airway epithelial (Hep-2) cells has been reported (18). Oxidative stress increased the expression 
of plasminogen activator inhibitor-1 (PAI-1), by mediating p38 phosphorylation in endothelial cells treated with copper oxide nanoparticles (42 and $200 \mathrm{~nm}$ ) (118). Elevated oxidative stress may lead to DNA damage, which in turn has the potential for carcinogenesis. In another study on A549 cells, copper oxide nanoparticles were the most potent with regard to cytotoxicity and DNA damage (119). The toxicity may have been caused by copper ions released in the cell medium. It was also observed that $\mathrm{CuZnFe}_{2} \mathrm{O}_{4}$ particles were rather potent in inducing DNA. Copper nanoparticles $(<100 \mathrm{~nm})$ were also shown to be more toxic to human A549 cells than copper fine particles (120) and were also reported to induce toxicity of sensory neurons (121). The latter study examined the concentration (10-100 $\mu \mathrm{M})$ and size-dependent (40, 60 and $80 \mathrm{~nm}$ ) effects of copper nanoparticles on the survival of dorsal root ganglion (DRG) neurons of rats in cell culture for $24 \mathrm{~h}$. The DRG neurons showed the presence of vacuoles and detachment of certain neurons from the substratum, they also exhibited disrupted neurite network in those exposed to copper nanoparticles. All the sizes tested had a significant toxic effect on DRG neurons compared to the controls. Copper was also shown to be intracellularly deposited by rubeanic acid staining.

The copper nanoparticles and their compounds caused a range of effects, including oxidative stress, cytotoxicity, neurotoxicity, DNA damage and DNA lesions in a variety of cell lines.

\section{In vivo studies}

According to the Hodge and Sterner scale, copper nanoparticle toxicity is class 3, moderately toxic. Chen et al (106), demonstrated that copper nanoparticles particularly target the liver, kidneys and spleen in experimental mice. At a particle size of $25 \mathrm{~nm}$ and dosage range of $108-1080 \mathrm{mg} / \mathrm{kg}$, copper nanoparticles caused atrophy of the spleen and discoloration of both the spleen and kidneys. Upon histopathological examination the kidneys exhibited glomerulonephritis. Alveolitis, perivasculitis and a significantly high lavage of cytokines were also observed. Cho et al (92) instilled well-characterized copper oxide nanoparticles into the lung of rats to evaluate their inflammatory potency. Two time points were used $(24 \mathrm{~h}$ and 4 weeks) to evaluate the acute and chronic effects of these particles. Their results showed that copper oxide nanoparticles at 10-20 and $<50 \mathrm{~nm}$, respectively, had acute and chronic inflammogenic effects on the lung. Acutely, patterns of the lung showed neutrophil and eosinophil infiltrates that differed following instillation. Chronically, the nanoparticles caused neutrophilic, neutrophilic/lymphocytic, eosinophilic/fibrotic/ granulomatous and fibrotic granulomatous inflammation.

Persistence of inflammation markers 3 weeks post-exposure was also observed by other investigators (122), who studied whole-body inhalation exposures performed on mice at concentrations of $3.6 \mathrm{mg} / \mathrm{m}^{3}$. Unresolved inflammation may lead to DNA aberrations that may be mutagenic. Yang et al (123) used male Wistar rats to investigate the mechanisms of copper nanoparticle-induced hepatotoxicity through identification from hepatic gene expression profiles that were phenotypically associated with conventional toxicological outcomes. Through histopathological studies of the rats administered with differing concentrations of copper nanoparticles and micro-copper (size unavailable), the liver exhibited scattered, punctate hepatocytic necrosis in all rats in the high-dose group. After functionally categorizing identified genes from the high-dose group, their results showed that genes related to oxidoreductase activity, metabolism and signal transduction were involved in the development of the phenotypes. Their study also demonstrated that there was an increase in aspartate transaminase, triglycerides, total bilirubin, total bile acid levels and a decrease in body weight. Punctate necrosis of hepatocytes in the liver was observed by another study which used nasal instillation of 23.5-nm copper nanoparticles in mice 3 times/week (124). They also observed swelling in the renal glomerulus and severe lesions associated with the decreased number of olfactory cells, and dilapidated laminated structures were also observed in the olfactory bulb. These were observed in the high-dose group (40 mg/kg body weight), but not in the low-dose group ( $1 \mathrm{mg} / \mathrm{kg}$ body weight). Sharma et al (125) examined neurotoxicity and neuropathology caused by silver, aluminum and copper nanoparticles that were approximately 50-60 $\mathrm{nm}$ in rats and mice. These were injected by intraperitoneal $(50 \mathrm{mg} / \mathrm{kg}$ body weight $)$, intraveneous (30 mg/kg body weight), intracarotid $(2.5 \mathrm{mg} / \mathrm{kg}$ body weight) or intracerebroventricular administration $(20 \mu \mathrm{g}$ to both mice and rats) at $24 \mathrm{~h}$ after administration. Alterations in the blood-brain barrier were observed in several regions of the brain and spinal cord through Evans blue and radioiodine studies. Decreased cerebral blood flow, pronounced brain edema, neuronal cell injuries, glial cell activation, heat shock protein upregulation and loss of myelinated fibers were observed in mice exposed to silver and copper nanoparticles, particularly when administered into the systemic circulation or the brain ventricular spaces.

As indicated by these studies, copper nanoparticles induce inflammation of organs, including the lung, kidney and spleen in mice. The most profound effects were observed in liver, even when the copper nanoparticle route of administration and animal model differed among studies. The copper nanoparticles were also shown to be neurotoxic and neuropathologic. However, apart from the induction of other types of pathology, none of these studies reported carcinogenesis.

\section{Conclusion}

The number of studies on these three transitional metalbased nanoparticles is limited, although direct genotoxicity endpoints for cobalt outweigh that of nickel and copper comparatively. Well-designed studies, particularly in vivo studies, are required to elucidate the genotoxicity and carcinogenicity of cobalt, nickel and copper nanoparticles. Overall, changes in gene expression, apoptosis, oxidative stress and persistent inflammation were the major effects of cobalt-, nickel- and copper-based nanoparticles that may predispose to carcinogenicity. Oxidative stress also poses a significant threat since it may lead to DNA, protein and lipid damage (126). The number of in vivo studies performed is far fewer than the in vitro studies for all three elements, whether as compounds or metals. With the exception of copper nanoparticles, both cobalt and nickel nanoparticles have been shown to be carcinogenic in vivo.

In conclusion, both in vitro and in vivo methods are useful in studying nanoparticle toxicity and carcinogenicity, 
but compared to in vivo and in vitro methods are much more time- and cost-efficient. Thus, the majority of studies have been performed using in vitro methods that utilize various cell lines $(86,127)$. It has now been documented that different nanoparticles elicit different responses from different cell lines or biological systems. With the exception of copper nanoparticles, cobalt and nickel nanoparticles have shown genotoxic effects and also cases of carcinogenesis in in vivo studies. The majority of in vivo studies utilize rats or mice as experimental animals. The existing studies on cobalt, nickel and copper have focused on the biological distribution of these particles following exposure through the lungs, skin and GIT.

The exact mechanisms of cobalt- and nickel-based nanoparticle-induced carcinogenesis in experimental animals are not clear. Enhanced oxidative stress, inflammatory response and abnormal apoptosis may play major roles in the carcinogenicity of cobalt- and nickel-based nanoparticleinduced carcinogenesis.

In addition, this review has shown that these metal-based nanoparticles (cobalt, nickel and copper) are particularly lacking in in vivo genotoxicity and carcinogenicity studies and it would be beneficial to further the knowledge of their genotoxicity and carcinogenicity. We also recommend more epidemiological studies to be performed on prosthetic implants that are cobalt-based and a clear definition of the particle size within studies.

\section{Acknowledgements}

This study was partly supported by the Ningbo Scientific Project (SZX11073), the Scientific Innovation Team Project of Ningbo (no. 2011B82014), the Foundations of Innovative Research Team of Educational Commission of Zhejiang Province (T200907), Innovative Research Team of Ningbo (2009B21002) and K.C. Wong Magna Fund in Ningbo University.

\section{References}

1. Klapper M, Nenov S, Haschick R, Müller K and Müllen K: Oil-in-oil emulsions: a unique tool for the formation of polymer nanoparticles. Acc Chem Res 41: 1190-1201, 2008.

2. Morimoto Y, Kobayashi N, Shinohara N, Myojo T, Tanaka I and Nakanishi J: Hazard assessments of manufactured nanomaterials. J Occup Health 52: 325-334, 2010.

3. Scuri M, Chen BT, Castranova V, et al: Effects of titanium dioxide nanoparticle exposure on neuroimmune responses in rat airways. J Toxicol Environ Health A 73: 1353-1369, 2010.

4. Buffle J: The key role of environmental colloids/nanoparticles for the sustainability of life. Environ Chem 3: 155-158, 2006.

5. Ng C, Li JJ, Bay B and Yung LL: Current studies into the genotoxic effects of nanomaterials. J Nucleic Acids 2010: 947859 2010.

6. Rushton EK, Jiang J, Leonard SS, et al: Concept of assessing nanoparticle hazards considering nanoparticle dosemetric and chemical/biological response metrics. J Toxicol Environ Health A 73: 445-461, 2010.

7. Buzea C, Pacheco II and Robbie K: Nanomaterials and nanoparticles: sources and toxicity. Biointerphases 2: MR17-MR71, 2007.

8. LeBlanc AJ, Cumpston JL, Chen BT, Frazer D, Castranova V and Nurkiewicz TR: Nanoparticle inhalation impairs endotheliumdependent vasodilation in subepicardial arterioles. J Toxicol Environ Health A 72: 1576-1584, 2009.

9. Oberdörster G: Pulmonary effects of inhaled ultrafine particles. Int Arch Occup Environ Health 74: 1-8, 2001.

10. Oberdörster G, Ferin J and Lehnert BE: Correlation between particle size, in vivo particle persistence, and lung injury. Environ Health Perspect 102 (Suppl 5): 173-179, 1994.
11. Liang G, Pu Y, Yin L, et al: Influence of different sizes of titanium dioxide nanoparticles on hepatic and renal functions in rats with correlation to oxidative stress. J Toxicol Environ Health A 72: 740-745, 2009.

12. Zhao J, Bowman L, Zhang X, et al: Titanium dioxide $\left(\mathrm{TiO}_{2}\right)$ nanoparticles induce JB6 cell apoptosis through activation of the caspase-8/Bid and mitochondrial pathways. J Toxicol Environ Health A 72: 1141-1149, 2009.

13. Gulumian M and Vallyathan V: Nanoparticles and potential human health implications: past and future directions. Preface. J Toxicol Environ Health A 73: 339-340, 2010.

14. Huang YC, Karoly ED, Dailey LA, et al: Comparison of gene expression profiles induced by coarse, fine, and ultrafine particulate matter. J Toxicol Environ Health A 74: 296-312, 2011.

15. Valko M, Rhodes CJ, Moncol J, Izakovic M and Mazur M: Free radicals, metals and antioxidants in oxidative stress-induced cancer. Chem Biol Interact 160: 1-40, 2006.

16. Ghio AJ, Carraway MS and Madden MC: Composition of air pollution particles and oxidative stress in cells, tissues, and living systems. J Toxicol Environ Health B Crit Rev 15: 1-21, 2012.

17. Shi X, Castranova V, Halliwell B and Vallyathan V: Reactive oxygen species and silica-induced carcinogenesis. J Toxicol Environ Health B Crit Rev 1: 181-197, 1998.

18. Fahmy B and Cormier SA: Copper oxide nanoparticles induce oxidative stress and cytotoxicity in airway epithelial cells. Toxicol In Vitro 23: 1365-1371, 2009.

19. Lin W, Stayton I, Huang Y, Zhou XD and Ma Y: Cytotoxicity and cell membrane depolarization induced by aluminum oxide nanoparticles in human lung epithelial cells A549. Toxicol Environ Chem 90: 983-996, 2008.

20. Lin W, Xu Y, Huang CC, Ma Y, Shannon KB, Chen DR and Huang YW: Toxicity of nano- and micro-sized $\mathrm{ZnO}$ particles in human lung epithelial cells. J Nanoparticle Res 11:25-39, 2009.

21. Lin W, Huang YW, Zhou XD and Ma Y: In vitro toxicity of silica nanoparticles in human lung cancer cells. Toxicol Appl Pharmacol 217: 252-259, 2006.

22. Lin W, Huang YW, Zhou XD and Ma Y: Toxicity of cerium oxide nanoparticles in human lung cancer cells. Int J Toxicol 25: 451-457, 2006.

23. Limbach LK, Wick P, Manser P, Grass RN, Bruinink A and Stark WJ: Exposure of engineered nanoparticles to human lung epithelial cells: Influence of chemical composition and catalytic activity on oxidative stress. Environ Sci Technol 41: 4158-4163, 2007.

24. Tabet L, Bussy C, Amara N, et al: Adverse effects of industrial multiwalled carbon nanotubes on human pulmonary cells. J Toxicol Environ Health A 72: 60-73, 2009.

25. Sohaebuddin SK, Thevenot PT, Baker D, Eaton JW and Tang L: Nanomaterial cytotoxicity is composition, size, and cell type dependent. Part Fibre Toxicol 7: 22, 2010.

26. Zhao $\mathrm{J}$ and Castranova V: Toxicology of nanomaterials used in nanomedicine. J Toxicol Environ Health B Crit Rev 14: 593-632, 2011.

27. Bhattacharya $\mathrm{K}$, Cramer $\mathrm{H}$, Albrecht $\mathrm{C}$, et al: Vanadium pentoxide-coated ultrafine titanium dioxide particles induce cellular damage and micronucleus formation in V79 cells. J Toxicol Environ Health A 71: 976-980, 2008.

28. Wang K, Xu JJ and Chen HY: A novel glucose biosensor based on the nanoscaled cobalt phthalocyanine-glucose oxidase biocomposite. Biosens Bioelectron 20: 1388-1396, 2005.

29. Martens JWD and Peeters WL: Anisotropy in cobalt-ferrite thin films. J Magn Magn Mater 61: 21-23, 1986.

30. Bouchard LS, Anwar MS, Liu GL, Hann B, Xie ZH, Gray JW, Wang X, Pines A and Chen FF: Picomolar sensitivity MRI and photoacoustic imaging of cobalt nanoparticles. Proc Natl Acad Sci USA 106: 4085-4089, 2009.

31. Seo WS, Lee JH, Sun X, Suzuki Y, Mann D, Liu Z, Terashima M, Yang PC, McConnel MV, Nishimura DG and Dai H: FeCo/ graphitic-shell nanocrystals as advanced magnetic-resonanceimaging and near-infrared agents. Nat Mater 5: 971-976, 2006.

32. Sadjadi MS, Pourahmad A, Sohrabnezhad Sh and Zare K: Formation of NiS and CoS semiconductor nanoparticles inside mordenite-type zeolite. Mater Lett 61: 2923-2926, 2006.

33. Florencio L, Field JA and Lettinga G: Importance of cobalt for individual trophic groups in an anaerobic methanol-degrading consortium. Appl Environ Microbiol 60: 227-234, 1994.

34. Council INI: Wastewater treatment using semiconductor nanocomposites. http://www.nanowerk.com/news/newsid=11840.php. 2011. 
35. Lison D, Lauwerys R, Demedts M and Nemery B: Experimental research into the pathogenesis of cobalt/hard metal lung disease. Eur Respir J 9: 1024-1028, 1996.

36. Lison D, De Boeck M, Verougstraete V and Kirsch-Volders M: Update on the genotoxicity and carcinogenicity of cobalt compounds. Occup Environ Med 58: 619-625, 2001.

37. Domingo JL: Metal-induced developmental toxicity in mammals: a review. J Toxicol Environ Health 42: 123-141, 1994.

38. Kuo CY, Wong RH, Lin JY, Lai JC and Lee H: Accumulation of chromium and nickel metals in lung tumors from lung cancer patients in Taiwan. J Toxicol Environ Health A 69: 1337-1344, 2006

39. De Boeck M, Kirsch-Volders M and Lison D: Cobalt and antimony: genotoxicity and carcinogenicity. Mutat Res 533: $135-152,2003$

40. Beyersmann D and Hartwig A: The genetic toxicology of cobalt. Toxicol Appl Pharmacol 115: 137-145, 1992.

41. Ponti J, Sabbioni E, Munaro B, Broggi F, Marmorato P, Franchini F, Colognato R and Rossi F: Genotoxicity and morphological transformation induced by cobalt nanoparticles and cobalt chloride: an in vitro study in Balb/3T3 mouse fibroblasts. Mutagenesis 24: 439-445, 2009.

42. Colognato R, Bonelli A, Ponti J, Farina M, Bergamaschi E, Sabbioni E and Migliore L: Comparative genotoxicity of cobalt nanoparticles and ions in human peripheral leukocytes in vitro. Mutagenesis 23: 377-382, 2008.

43. Kwon Y, Xia Z, Glyn-Jones S, Beard D, Gill HS and Murray D: Dose-dependent cytotoxicity of clinically relevant cobalt nanoparticles and ions on macrophages in vitro. Biomed Mater 4: 025018, 2009

44. Peters K, Unger RE, Gatti AM, Sabbioni E, Tsaryk R and Kirkpatrick CJ: Metallic nanoparticles exhibit paradoxical effects on oxidative stress and pro-inflammatory response in endothelial cells in vitro. Int J Immunopathol Pharmacol 20: 685-695, 2007.

45. Papageorgiou I, Brown C, Schins R, Singh S, Newson R, Davis S, Fisher J, Ingham E and Case CP: The effect of nano- and micronsized particles of cobalt-chromium alloy on human fibroblasts in vitro. Biomaterials 28: 2946-2958, 2007.

46. Figgitt M, Newson R, Leslie IJ, Fisher J, Ingham E and Case CP: The genotoxicity of physiological concentrations of chromium ( $\mathrm{Cr}(\mathrm{III})$ and $\mathrm{Cr}(\mathrm{VI}))$ and cobalt (Co(II)): an in vitro study. Mutat Res 688: 53-61, 2010.

47. Tsaousi A, Jones $\mathrm{E}$ and Case $\mathrm{CP}$ : The in vitro genotoxicity of orthopaedic ceramic $\left(\mathrm{Al}_{2} \mathrm{O}_{3}\right)$ and metal $(\mathrm{CoCr}$ alloy) particles. Mutat Res 697: 1-9, 2010.

48. Bhabra G, Sood A, Fisher B, Cartwright L, Saunders M, Evans WH, Surprenant A, Lopez-Castejon G, Mann S, Davis SA, et al: Nanoparticles can cause DNA damage across a cellular barrier. Nat Nanotechnol 4: 876-883, 2009.

49. Parry MC, Bhabra G, Sood A, Machado F, Cartwright L, Saunders M, Ingham E, Newson R, Blom AW and Case CP: Thresholds for indirect DNA damage across cellular barriers for orthoaedic biomaterials. Biomaterials 31: 4477-4483, 2010.

50. Grassian VH, Adamcakova-Dodd A, Pettibone JM, O'shaughnessy PT and Thorne PS: Inflammatory response of mice to manufactured titanium dioxide nanoparticles: comparison of size effects through different exposure routes. Nanotoxicology 1: 211-226, 2007.

51. Monteiller C, Tran L, MacNee W, Faux S, Jones A, Miller B and Donaldson K: The pro-inflammatory effects of low-toxicity lowsolubility particles, nanoparticles and fine particles, on epithelial cells in vitro: the role of surface area. Occup Environ Med 64: 609-615, 2007.

52. Sayes CM, Reed KL and Warheit DB: Assessing toxicity of fine and nanoparticles: comparing in vitro measurements to in vivo pulmonary toxicity profiles. Toxicol Sci 97: 163-180, 2007.

53. Park E and Park K: Oxidative stress and pro-inflammatory responses induced by silica nanoparticles in vivo and in vitro. Toxicol Lett 184: 18-25, 2009.

54. Carlson C, Hussain SM, Schrand AM, Braydich-Stolle LK, Hess KL, Jones RL and Schlager JJ: Unique cellular interaction of silver nanoparticles: size-dependent generation of reactive oxygen species. J Phys Chem B 112: 13608-13619, 2008.

55. Guildford AL, Poletti T, Osbourne LH, Di Cerbo A, Gatti AM and Santin M: Nanoparticles of a different source induce different patterns of activation in key biochemical and cellular components of the host response. J R Soc Interface 6: 1213-1221, 2009 .
56. Singh N, Manshian B, Jenkins GJ, Griffiths SM, Williams PM, Maffeis TG, Wright CJ and Doak SH: NanoGenotoxicology: the DNA damaging potential of engineered nanomaterials. Biomaterials 30: 3891-3894, 2009.

57. Wang $\mathrm{H}$ and $\mathrm{Cho} \mathrm{CH}$ : Effect of NF- $\mathrm{NB}$ signaling on apoptosis in chronic inflammation-associated carcinogenesis. Curr Cancer Drug Targets 10: 593-599, 2010.

58. Papis E, Rossi F, Raspanti M, Dalle-Donne I, Colombo G, Milzani A, Bernadini G and Gornati R: Engineered cobalt oxide nanoparticles readily enter cells. Toxicol Lett 189: 253-259, 2009.

59. Anard D, Kirsch-Volders M, Elhajouji A, Belpaeme K and Lison D: In vitro genotoxic effects of hard metal particles assessed by alkaline single cell gel and elution assays. Carcinogenesis 18: 177-184, 1997.

60. Ding M, Kisin ER, Zhao J, Bowman L, Lu Y, Jiang B, Leonard S, Vallyathan V, Castranova V, Murrray AR, et al: Size-dependent effects of tungsten carbide-cobalt particles on oxygen radical production and activation of cell signaling pathways in murine epidermal cells. Toxicol Appl Pharmacol 241: 260-268, 2009

61. Busch W, Kühnel D, Schirmer K and Scholz S: Tungsten carbide cobalt nanoparticles exert hypoxia-like effects on the gene expression level in human keratinocytes. BMC Genomics 11: 65 , 2010.

62. Zhang XD, Zhao J, Bowman L, Shi X, Castranova V and Ding M: Tungsten carbide-cobalt particles activate Nrf2 and its downstream target genes in JB6 cells possibly by ROS generation. J Environ Pathol Toxicol Oncol 29: 31-40, 2010.

63. Pershina AG, Sazonov AE, Novikov DV, et al: Study of DNA interaction with cobalt ferrite nanoparticles. J Nanosci Nanotechnol 11: 2673-2677, 2011.

64. Hansen T, Clermont G, Alves A, Eloy R, Brochhausen C, Boutrand JP, Gatti AM and Kirkpatrick CJ: Biological tolerance of different materials in bulk and nanoparticulate form in a rat model: sarcoma development by nanoparticles. J R Soc Interface 3: 767-775, 2006

65. Ban I, Stergar J, Drofenik M, Ferk G and Makovec D: Synthesis of copper-nickel nanoparticles prepared by mechanical milling for use in magnetic hyperthermia. J Magn Magn Mater 323: 2254-2258, 2011

66. Chou KS, Chang CS and Huang KC: Study on the characteristics of nanosized nickel particles using sodium borohydride to promote conve. AZojomo 3: 2007. doi:10.2240/azojomo0232.

67. Zhu FQ, Chern GW, Tchernyshyov O, Zhu XC, Zhu JG and Chien CL: Magnetic bistability and controllable reversal of asymmetric ferromagnetic nanorings. Phys Rev Lett 96: 027205, 2006.

68. Zhao J, Shi X, Castranova V and Ding M: Occupational toxicology of nickel and nickel compounds. J Environ Pathol Toxicol Oncol 28: 177-208, 2009

69. Cameron KS, Buchner V and Tchounwou PB: Exploring the molecular mechanisms of nickel-induced genotoxicity and carcinogenicity: a literature review. Rev Environ Health 26: 81-92, 2011.

70. Kasprzak KS, Sunderman FW Jr and Salnikow K: Nickel carcinogenesis. Mutat Res 533: 67-97, 2003.

71. Kornick R and Zug KA: Nickel. Dermatitis 19: 3-8, 2008.

72. Tang X, Li C and Wu W: Research progress on carcinogenicity of nickel and its compounds. Chinese Journal of Industrial Medicine 4: 276-279, 2010 (In Chinese)

73. Oller AR: Respiratory carcinogenicity assessment of soluble nickel compounds. Environ Health Perspect 110 (Suppl 5): 841-844, 2002

74. Seilkop SK and Oller AR: Respiratory cancer risks associated with low-level nickel exposure: an integrated assessment based on animal, epidemiological, and mechanistic data. Regul Toxicol Pharmacol 37: 173-190, 2003.

75. Grimsrud TK, Berge SR, Resmann F, Norseth T and Andersen A: Assessment of historical exposures in a nickel refinery in Norway. Scand J Work Environ Health 26: 338-345, 2000.

76. Goodman JE, Prueitt RL, Thakali S and Oller AR: The nickel ion bioavailability model of the carcinogenic potential of nickelcontaining substances in the lung. Crit Rev Toxicol 41: 142-174, 2011.

77. Costa M, Yan Y, Zhao D and Sainikow K: Molecular mechanisms of nickel carcinogenesis: gene silencing by nickel delivery to the nucleus and gene activation/inactivation by nickel-induced cell signaling. J Environ Monit 5: 222-223, 2003. 
78. Zhang Q, Kusaka Y, Zhu X, et al: Comparative toxicity of standard nickel and ultrafine nickel in lung after intratracheal instillation. J Occup Health 45: 23-30, 2003.

79. Kyono H, Kusaka Y, Homma K, Kubota H and Endo-Ichikawa Y: Reversible lung lesions in rats due to short-term exposure to ultrafine cobalt particles. Ind Health 30: 103-118, 1992.

80. Maynard AD and Kuempel ED: Airborne nanostructured particles and occupational health. J Nanopart Res 7: 587-614, 2005 .

81. NIPERA: Safe Use of Nickel in the Workplace - Incorporating European Nickel Risk Assessment Outcomes. A guide for Health Maintenance of Workers Exposed to Nickel, Its Compounds and Alloys - Health guide. 3rd edition. Nickel Producers Environmental Research Association, Durham, NC, USA, 2008.

82. Park S, Lee YK, Jung M, Kim KH, Chung N, Ahn EK, Lim Y and Lee KH: Cellular toxicity of various inhalable nanoparticles on human alveolar epithelial cells. Inhal Toxicol 19 (Suppl 1): $59-65,2007$

83. Nagata S: Apoptotic DNA fragmentation. Exp Cell Res 256: $12-18,2000$.

84. Yang H, Liu C, Yang D, Zhang H and Xi Z: Comparative study of cytotoxicity, oxidative stress and genotoxicity induced by four typical nanomaterials: the role of particle size, shape and composition. J Appl Toxicol 29: 69-78, 2009.

85. Pujalté I, Passagne I, Daculsi R, Brouillaud B, Rémy M, Tréguer M, DePortal C, Ohayon-Courtès C and L'Azou B: Toxicity and oxidative stress induced by metallic nanoparticles in renal cells. Proceeding of the Annual Meeting of the French Society of Toxicology 2010. Paris, 2010 (Available at: http:// www.sftox.com/congres/sft2010/posters/index.html).

86. Zhao J, Bowman L, Zhang X, Shi X, Jiang B, Castranova V and Ding M: Metallic nickel nano- and fine particles induce JB6 cell apoptosis through a caspase-8/AIF mediated cytochrome c-independent pathway. J Nanobiotechnology 7: 2, 2009.

87. Ryter SW, Kim HP, Hoetzel A, et al: Mechanisms of cell death in oxidative stress. Antioxid Redox Signal 9: 49-89, 2007.

88. Guo D, Wu C, Li X, Jiang H, Wang X and Chen B: In vitro cellular uptake and cytotoxic effect of functionalized nickel nanoparticles on leukemia cancer cells. J Nanosci Nanotechnol 8: 2301-2307, 2008.

89. Pietruska JR, Liu X, Smith A, McNeil K, Weston P, Zhitkovich A, Hurt R and Kane AB: Bioavailability, intracellular mobilization of nickel, and HIF-1 $\alpha$ activation in human lung epithelial cells exposed to metallic nickel and nickel oxide nanoparticles. Toxicol Sci 124: 138-148, 2011

90. Ahamed M: Toxic response of nickel nanoparticles in human lung epithelial A549 cells. Toxicol In Vitro 25: 930-936, 2011.

91. Horie M, Fukui H, Nishio K, Endoh S, Kato H, Fujita K, Miyauchi A, Nakamura A, Shichiri M, Ishida N, et al: Evaluation of Acute Oxidative Stress Induced by $\mathrm{NiO}$ Nanoparticles In Vivo and In Vitro. J Occup Health 53: 64-74, 2011.

92. Cho WS, Duffin R, Poland CA, Howie SE, MacNee W, Bradley M, Megson IL and Donaldson K: Metal oxide nanoparticles induce unique inflammatory footprints in the lung: important implications for nanoparticle testing. Environ Health Perspect 118: 1699-1706, 2010.

93. Iannitti T, Capone S, Gatti A, Capitani F, Cetta F and Palmieri B Intracellular heavy metal nanoparticle storage: progressive accumulation within lymph nodes with transformation from chronic inflammation to malignancy. Int J Nanomedicine 5: 955-960, 2010.

94. Phillip JI, Green FY, Davis JCA and Murray J: Pulmonary and systemic toxicity following exposure to nickel nanoparticles. Am J Ind Med 53: 763-767, 2010.

95. Gillespie PA, Kang GS, Elder A, Gelein R, Chen L, Moreira AL, Koberstein J, Tchou-Wong KM, Gordon T and Chen LC: Pulmonary response after exposure to inhaled nickel hydroxide nanoparticles: short and long-term studies in mice. Nanotoxicology 4: 106-119, 2010.

96. Morimoto Y, Ogami A, Todoroki M, Yamamoto M, Murakami M, Hirohashi M, Oyabu T, Myojo T, Nishi K, Kadoya C, et al: Expression of inflammation-related cytokines following intratracheal instillation of nickel oxide nanoparticles. Nanotoxicology 4: 161-176, 2010.

97. Morimoto Y, Hirohashi M, Ogami A, Oyabu T, Myojo T, Hashiba M, Mizuquchi Y, Kambara T, Lee BW, Kuroda E and Tanaka I: Pulmonary toxicity following an intratracheal instillation of nickel oxide nanoparticle agglomerates. J Occup Health 53: 293-295, 2011.
98. Nishi K, Morimoto Y, Ogami A, Murakami M, Myojo T, Oyabu T, Kadoya C, Yamamoto M, Todoroki M, Hirohashi M, et al: Expression of cytokine-induced neutrophil chemoattractant in rat lungs by intratracheal instillation of nickel oxide nanoparticles. Inhal Toxicol 21: 1030-1039, 2009.

99. Kang GS, Gillespie PA, Gunnison A, Rengifo H, Koberstein J and Chen LC: Comparative pulmonary toxicity of inhaled nickel nanoparticles; role of deposited dose and solubility. Inhal Toxicol 23: 95-103, 2011.

100. Brown TJ, Bide T, Walters AS, Idoine NE, Shaw RA, Hannis SD, Lusty PAJ and Kendall R: World Mineral Production 2005-09. British Geological Survey, Nottingham, UK, 2011.

101. Olivares M and Uauy R: Copper as an essential nutrient. Am J Clin Nutr 63: 791S-796S, 1996.

102. Chambers A, Krewski D, Birkett N, et al: An exposure-response curve for copper excess and deficiency. J Toxicol Environ Health B Crit Rev 13: 546-578, 2010.

103. Stern BR, Solioz M, Krewski D, et al: Copper and human health: biochemistry, genetics, and strategies for modeling doseresponse relationships. J Toxicol Environ Health B Crit Rev 10: 157-222, 2007.

104. Failla ML: Trace elemnts and host defense: recent advances and continuing challenges. J Nutr 133 (5 Suppl 1): 1443S-1447S, 2003.

105. Tapiero H, Townsend DM and Tew KD: Trace elements in the human physiology and pathology. Copper. Biomed Pharmacother 57: 386-398, 2003.

106. Chen Z, Meng H, Xing GM, Chen CY, Zhao YL, Jia G, Wang T, Yuan H, Ye C, Zhao F, et al: Acute toxicological effects of copper nanoparticles in vivo. Toxicol Lett 163: 109-120, 2006.

107. Kempson IM, Skinner WM and Kirkbride KP: The occurrence and incorporation of copper and zinc in hair and their potential role as bioindicators: a review. J Toxicol Environ Health B Crit Rev 10: 611-622, 2007.

108. Cioffi N, Ditaranto N, Torsi L, Picca RA, Sabbatini L, Valentini A, Novello L, Tantillo G, Bleve-Zacheo T and Zambonin PG: Analytical characterization of bioactive fluoropolymer ultra-thin coatings modified by copper nanoparticles. Anal Bioanal Chem 381: 607-616, 2005.

109. Athanassiou EK, Grass RN and Stark WJ: Large-scale production of carbon-coated copper nanoparticles for sensor applications. Nanotechnology 17: 1668, 2006.

110. Hahn A, Günther S, Wagener P and Barcikowski S: Electrochemistry-controlled metal ion release from silicone elastomer nanocomposites through combination of different metal nanoparticles. J Mater Chem 21: 10287-10289, 2011

111. De Oliveira JV, Boufleur LA, Dos Santos CE, et al: Occupational genotoxicity among copper smelters. Toxicol Ind Health: Oct 31 , 2011 (Epub ahead of print).

112. Bhunya SP and Jena GB: Clastogenic effects of copper sulphate in chick in vivo test system. Mutat Res 367: 57-63, 1996.

113. Agarwal K, Sharma A and Talukder G: Clastogenic effects of copper sulphate on the bone marrow chromosomes of mice in vivo. Mutat Res 243: 1-6, 1990.

114. Meng H, Chen Z, Xing GM, Yuan H, Chen CY, Zhao F, Zhang CC, Wang Y and Zhao YL: Ultra high reactivity and grave nanotoxicity of copper nanoparticles. Journal of Radioanalytical and Nuclear Chemistry 272: 595-598, 2007.

115. Jose GP, Santra S, Mandal SK and Sengupta TK: Singlet oxygen mediated DNA degradation by copper nanoparticles: potential towards cytotoxic effect on cancer cells. J Nanobiotechnology 9: 9,2011

116. Dolmans DE, Fukumura D and Jain RK: Photodynamic therapy for cancer. Nat Rev Cancer 3: 380-387, 2003

117. Petersen EJ and Nelson BC: Mechanisms and measurements of nanomaterial-induced oxidative damage to DNA. Anal Bioanal Chem 398: 613-650, 2010.

118. Yu M, Mo Y, Wan R, Chien S, Zhang X and Zhang Q: Regulation of plasminogen activator inhibitor-1 expression in endothelial cells with exposure to metal nanoparticles. Toxicol Lett 195: $82-89,2010$

119. Karlsson HL, Cronholm P, Gustafsson J and Möller L: Copper oxide nanoparticles are highly toxic: a comparison between metal oxide nanoparticles and carbon nanotubes. Chem Res Toxicol 21: 1726-1732, 2008 .

120. Karlsson HL, Gustafsson J, Cronholm P and Moller L: Sizedependent toxicity of metal oxide particles - a comparison between nano- and micrometer size. Toxicol Lett 188: 112-118, 2009. 
121. Prabhu BM, Ali SF, Murdock RC, Hussain SM and Srivatsan M: Copper nanoparticles exert size and concentration dependent toxicity on somatosensory neurons of rat. Nanotoxicology 4 : 150-160, 2010.

122. Pettibone JM, Adamcakova-Dodd A, Thorne PS O'Shaughnessy PT, Weydert JA and Grassian VH: Inflammatory response of mice following inhalation exposure to iron and copper nanoparticles. Nanotoxicology 2: 189-204, 2008.

123. Yang B, Wang Q, Lei R, Wu C, Shi C, Wang Q, Yaun Y, Wang Y, Luo Y, Hu Z, Ma H and Liao M: Systems toxicology used in nanotoxicology: mechanistic insights into the hepatotoxicity of nano-copper particles from toxicogenomics. J Nanosci Nanotechnol 10: 8527-8537, 2010

124. Liu Y, Gao Y, Zhang L, Wang T, Wang J, Jiao F, Li W, Liu Y, Li Y, Li B, Chai Z, Wu G and Chen C: Potential health impact on mice after nasal instillation of nano-sized copper particles and their translocation in mice. J Nanosci Nanotechnol 9: 6335-6343, 2009.
125. Sharma HS, Ali SF, Hussain S, Schlager JJ and Sharma A: Influence of engineered nanoparticles from metals on the bloodbrain barrier permeability, cerebral blood flow, brain edema and neurotoxicity. An experimental study in the rat and mice using biochemical and morphological approaches. J Nanosci Nanotechnol 9: 5055-5072, 2009.

126. Martindale JL and Holbrook NJ: Cellular response to oxidative stress: signaling for suicide and rvival. J Cell Physiol 192: 1-15, 2002.

127. Huang YW, Wu CH and Aronstam RS: Toxicity of transition metal oxide nanoparticles: recent insights from in vitro studies. Materials 3: 4842-4859, 2010. 